\title{
Aerosol and splatter in Dentistry - An Overview
}

\author{
Preetham Pulluri', Sowmya Nagur Karibasappa², Dhoom Singh Mehta ${ }^{3}$
}

Postgraduate Student, ${ }^{1}$ Reader, ${ }^{2}$ Professor and Head, ${ }^{3}$

Department of Periodontics, Bapuji Dental College and Hospital, Davangere, Karnataka State, India.

\section{Abstract:}

The environment in which we are surrounded is the sum total of living organisms like animals, plants and microorganisms and their actions which undergo constant changes, especially by human activity. It provides conditions for development and growth and also that of danger and damage. Aerosols are such products seen in the urban ecosystems in various forms. The presence of aerosols in earth's atmosphere can influence earth's climate, as well as human health. As they are omnipresent they form a universal challenge to all the dentists around the world to control their transmission and inhibit their action. Hence, in this article we have reviewed various properties of aerosols, methods of measurements, mode of transmission and standard precautions to be followed.

Keywords: Aerosol, Aerosol contamination in dentistry, Infection control, Splatter, Ultrasonic scaling.

\section{Introduction}

The microorganisms present in the environment have evolved in many ways to enable their existence. Introduction of contaminants into the environment can be one of the methods of transmission of these organisms into the host. They can either be natural or synthetic particles. These particles can cause adverse effects and might be harmful to the health. Example of such particles is aerosol.

An aerosol is defined as a colloidal system of solid or liquid particles in a gas. It includes both the particles and the suspending gas, which is usually air. ${ }^{1}$ The particles are colloidal in nature and are a major concern if present in exceeding levels. It was Frederick Donnan who first used the term aerosol during World War I to describe an aero-solution, clouds of microscopic particles in air. This term developed analogously to the term hydrosol, a colloid system with water as the dispersing medium. These particles are of 2 types

i) Primary aerosols- contain particles introduced directly into the gas

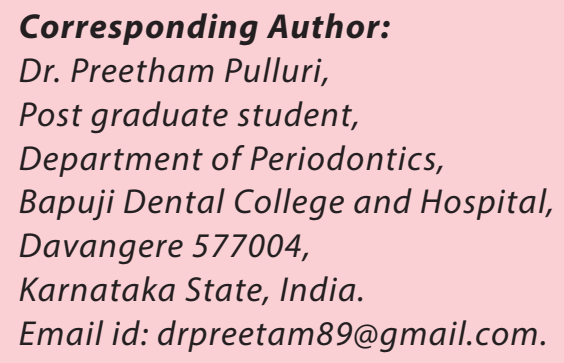

ii) Secondary aerosols- form through gas-to-particle conversion. ${ }^{2}$

In 1968 Micik et al defined dental aerosols as particles that are smaller than 50 micrometers and splatter as particles that are larger than 50 micrometers. ${ }^{3}$

There are several measures of aerosol concentration. Environmental science and health often uses the mass concentration (M) and is denoted as $\mu \mathrm{g} / \mathrm{m}^{3}$. Another commonly used measure is the number concentration $(\mathrm{N})$ and is denoted as number $/ \mathrm{m} 3$ or number $/ \mathrm{cm}^{3,4}$.

\section{Bio-aerosols in Dentistry}

Bioaerosol is a suspension of airborne particles that contain living organisms or were released from living organisms..$^{5}$ These particles are very small and range in size from less than one micrometer $(0.00004 ")$ to one hundred micrometers (0.004").In dentistry, bioaerosols are an important consideration for infection control and occupational health, as infections can be transmitted to patients or dental staff within the dental confinement. ${ }^{6}$

The most intensive aerosol and splatter emission occurs during the work of an ultrasonic scaler tip and a bur on a high-speed handpiece. The air-water combination produced during the treatment combines with the surrounding atmosphere and influences its composition. It has also been found that the micro-organisms colonize the dental equipment, the dental unit water lines forming a biofilm. This combination of bioaerosol is breathed by the dental staff and the patient, hence it is very important to be aware of the potential hazards and take appropriate measures. ${ }^{7}$ 


\section{Methods of measurement}

Quite a few methods are available for measurement of aerosols. Physical characterization of aerosols is done by differential mobility analysis, inertial separation and scanning electron microscopy whereas chemical characterizations of aerosols is done by aerodynamic sizing, fluorescence spectroscopy, chromatography, electrophoresis, immunosorpstion and DNA analysis.

But in the dental environment, the measurement was mainly done by counting the number of bacteria that settle on a growth media plate over a period of time. Later the numbers of colony forming units (CFU's) are measured. This method gives us a good idea regarding the aerosols produced during a particular procedure.

The most commonly found bacteria are of Bacillus species, Streptococci and Staphylococci species. Levels greater than $500 \mathrm{CFU} / \mathrm{m} 3$ is considered as high level of contamination but there is no international standards giving the maximum values of bacterial aerosols allowable for inflectional control in dental clinics.

\section{Composition}

The composition of aerosol and splatter is of prime concern because it affects the quality of air in a dental setup. Various factors affecting the composition of these aerosol particles are- its size, shape, density, microflora of DUWL (Dental unit water lines), oral flora of patient, type of treatment. ${ }^{7,8}$

Mechanical debridement during oral prophylaxis and use of high speed hand piece are the two most common causes of aerosols. During these procedures, it has been shown that there is emission of great amount of aerosol and splatter upto 7 feet. $^{9}$

Secretions of nasopharynx, saliva, plaque, tooth components, blood and various materials used for the treatment will be present in aerosols and scatter around the environment. ${ }^{10}$

\section{Microflora present in aerosol}

The most predominant bacteria seen during aerosol emission in a dental setup are Streptococcus at around $42 \%$ and Staphylococcus species around $41 \%$ of the total. ${ }^{7,11,12}$

Other infective bacteria have also been observed. These include-

\section{Bacteria}

Infectious diseases may arise from the bacteria, virus, and fungi due to their transmission from source to a susceptible host. Most common bacteria present in aerosol that may cause disease are- Streptococci species, Staphylococci species, Legionella, M.tuberculosis, Bacillus anthracis and the endotoxins released by gram negative organisms. $1^{1,12}$

\section{Fungi}

The fungi which are present in aerosols cause respiratory infections and allergic reactions. These include Penicillium, Aspergillus, Acremonium, Paecilomyces, Mucor and Cladosporium. ${ }^{11}$ Most infections, commonest being Aspergillosis, can occur in immunocompromised hosts or as a secondary infection, following inhalation of fungal spores or the toxins produced by them.

\section{Virus}

Viruses are readily transmitted by airborne route, and include SARS virus, enteric viruses of intestinal origin produced at sewage treatment facilities, RSV, Hantavirus from rodent faeces, varicella - zoster virus, measles, mumps and rubella viruses. Spread of the infection due to aerosolisation of laboratory strains has been reported, resulting in revised safety recommendations for laboratory personnel working with rabies virus. ${ }^{11}$

\section{Source and distribution}

Bioaerosols can arise from either a manmade or natural surfaces. These can be air systems, ceilings, carpets, operating room and aeration tanks. ${ }^{13}$ In the dental clinic, aerosols may originate from various sources like patients, staff, visitors, air conditioning system, DUWL. In addition to aerosols produced by coughing, dental procedures like ultrasonic scaling, air-water syringe 14 and even use of lasers in endodontic treatment causes aerosol production. ${ }^{15}$ Sinks, wash basins and drains can be a source of gram negative bacteria. Sweeping of the floor can also cause suspension of bio-aerosols. ${ }^{14}$

Dental aerosol and splatter affect the microbiological quality of air in a dental surgery. Most aerosols vary in their size and the ones found in a dental environment are less than 5 micrometer in diameter. ${ }^{15,16}$ Splatters can be distinguished from aerosols by their large size at around 100um. As opposed to aerosols that are widespread, splatter is mainly found near the immediate surroundings of its origin. Some studies have shown that 
ultrasonic scaling produces more aerosols than high speed dental drill, if the patient wore a rubber dam. ${ }^{17}$ But recent studies show that there is not much difference in the both the procedures. ${ }^{18}$

\section{Modes of transmission}

The transport of bioaerosols is affected by its physical properties and the environmental factors. Environmental factors that have an influence the transmission: these are air currents, humidity and temperature. ${ }^{19}$

During the dental procedures the areas showing highest microbial contamination are: doctors and assistant's masks. Unit lamp, surfaces close to spittoons and mobile instrument-material tables. ${ }^{20}$ These bioaerosols can be transmitted either at long distances even beyond the patient room environment. Smaller particles are transmitted to the person closer to the area of patient. Smaller particles travel longer distances as compared to larger particles. ${ }^{21}$

Even the air-conditioning systems and poorly maintained ventilation systems can be a source of microbes and their products present in the dental clinic. Some of these aerosols remain in the dental clinic and then recirculate again on the next day. ${ }^{22}$

According to Harrel and Molinari ${ }^{10}$ there are different modes of transmission for different organisms.

\begin{tabular}{|l|l|}
\hline DISEASE & MODE OF TRANSMISSION \\
\hline Plague & Direct inhalation \\
\hline Tuberculosis and influenza & Droplet nuclei expelled by patient through coughing \\
\hline Legionella species & Associated with air-conditioning systems \\
\hline Severe Acute Respiratory Syndrome & Direct contact from aerosolized droplets. \\
\hline
\end{tabular}

\section{Types of diseases caused by aerosols}

Aerosols are transmitted via gaseous suspension of fine liquid or solid particles. Numerous studies have shown that fine suspended particles in the dental environment can lead to disease transmission which can lead to severe health defects involving cardiovascular, respiratory systems and also cause allergic diseases. The types of disease caused by aerosol may vary among different people. It depends on the immunity of the individual, composition and types of organisms present in the aerosol. ${ }^{13}$

\begin{tabular}{|l|l|}
\hline ORGANISM & DISEASE \\
\hline C.diphtheria & Pharyngeal diphtheria \\
\hline H.influenza & Influenza \\
\hline H,influenza Type B, N.Meningitidis & Meningitis \\
\hline Mumps virus & Mumps \\
\hline A.flavus, A.fumigatus & $\begin{array}{l}\text { Nosocomial infection, allergic } \\
\text { bronchopulomonary aspergillosis and } \\
\text { sinusitis. }\end{array}$ \\
\hline SARS virus & Common cold \\
\hline Acanthamoeba, N.fowleri & SARS \\
\hline & Respiratory illness and \\
& meningoencephalitis. \\
\hline
\end{tabular}

\section{Methods to reduce aerosols}

Results obtained by researchers point to the importance of routine monitoring of microbiological contamination that occurs during dental surgeries like on the surface of instruments and devices, air and dental unit water, and - in the case of their contamination - the need for sterilization and disinfection. The following principles should be followed in order to reduce the risk resulting from the use of a dental unit and exposure to aerosol ${ }^{11}$.

1. The necessity for routine sterilization and disinfection. external sterility of dental handpiece can be achieved with autoclaving whereas internal sterility can be achieved by chemiclave. This is because the spores inside the high speed handpieces may survive autoclaving therefore it has to be treated internally with chemical disinfectant. ${ }^{23}$

2. Rinsing the oral cavity of a patient with an antiseptic, e. g. chlorhexidine, before a procedure. Various mouthrinses and expectorants have been used as preprocedural agents, such as: $0.001 \%$ Merthiolate, Nitromersol, $0.5 \%$ povidone iodine, $5 \%$ sodium chloride, 5\% lithium chloride, and 3\% hydrogen peroxide and $0.1 \%$ chlorine dioxide. ${ }^{24}$ 
Comparative studies done with mouthwashes containing $11.6 \%$ alcoholic solution, $0.12 \%$ chlorhexidine, $21.6 \%$ alcohol solution and water showed that chlorhexidine mouthwash generated fewer CFU's. ${ }^{25}$ This method reduces the number of microorganisms that may escape the patient's mouth during dental care through aerosols, spatter, or direct contact.

3. A dental unit should be rinsed at the beginning of a working day, and between patients. The first type of rinsing assures elimination of microflora whereas the second type aims at elimination of potential cross infection.

4. Use of devices reducing air contamination in a dental surgery.

Studies have shown that use of an ultrasonic scaler along with aerosol reduction device reduced the aerosols considerably. When focused coolant inserts were used, $72 \%$ reduction in contamination was noticed. ${ }^{26}$ Other systems like Air Cleaning Systems, High volume evacuators have shown significant reductions in production of bioaerosols. ${ }^{14,27,}$ 28

5. The quality of water should be monitored with the use of commercial laboratory tests. The water line has to be flushed at the start of each clinical day and between patients, for 30 seconds to 1 minute to reduce microbial accumulation due to overnight waterline stagnation.

6 . Valves must be used to prevent suckback of liquids into DUWL.

7. Usage of personnel protective equipment are the gloves, eye wear, faceshields, apron and masks. (Fig. 1)

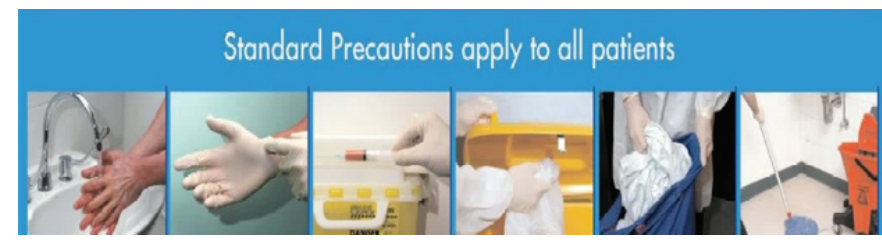

Fig. 1: Shows the standard precautions to be followed and the personnel protective equipments to be used.

\section{Fundamentals in prevention of aerosol transmission}

According to Szymanska insufficient awareness of health risk, working habits, and economic factors are the reasons why dentists do not apply the recommended methods of protection against the influence of bioaerosol and splatter. $^{7}$

CDC report in 2007 has released some of the fundamental elements to prevent aerosol transmission and infection control. ${ }^{29}$

1. Adherence of healthcare personnel to recommended guidelines.

2. Surveillance for healthcare-associated infections (HAIs).

3. Education of healthcare workers, patients.

4. Hand hygiene.

5. Personal protective equipment for healthcare personnel like gloves, isolation gowns, and face protection: masks, goggles, face shields.

6. Safe work practices to prevent exposure to bloodborne pathogens

7. Proper waste disposal measures.

\section{Conclusion}

It can be concluded that all the doctors must take adequate measures to reduce if not eliminate the aerosols. Proper sterilization techniques must be followed and instructions must be given to hygienists and other working staff in the dental environment regarding isolation and infection control methods.

\section{References}

1. Hinds WC. Aerosol Technology: properties, behavior, and management of airborne particles. New York: Wiley 1982, Pg. No 6.

2. Hidy, George M. Aerosols, an Industrial and Environmental Science. Academic Press, Inc. 1984, Pg. No. 254.

3. Micik RE, Miller RL, Mazzarella MA, Ryge G. Studies on aerobiology: bacterial aerosols generated during dental procedures. J Dent Res 1968; 48: 49-56.

4. Hinds WC. Aerosol Technology: properties, behavior, and management of airborne particles. New York: Wiley 1982: Pg. No 10.

5. Miller, RL, Micik, RE, Abel, C, Ryge, G. Studies of dental aerobiology, II: microbial splatter discharged from the oral cavity of dental patients. J Dent Res. 1971; 50: 621-625.

6. Jakush J. Infection control in the dental office: a realistic approach. J Am Dent Assoc 1986; $112: 458-68$ 
7. Szymanska J. Dental bioaerosol as an occupational hazard in a dentist's workplace. Ann Agric Environ Med 2007; 14:203-07.

8. Srikanth P, Sudharsanam S, Steinberg R. Bio-aerosols in indoor environment: composition, health effects and analysis. Indian $\mathrm{J}$ Med Microbiol. 2008; 26:302-12.

9. Wirthlin MR, Choi JH, Kye SB. Use of chlorine dioxide mouthrinse as the ultrasonic scaling lavage reduces the viable bacteria in the generated aerosols. J West Soc Periodontol Periodontal Abstr. 2006; 54:35-44.

10.Harrel SK, Molinari J. Aerosols and splatter in dentistry: a brief review of the literature and infection control implications. J Am Dent Assoc. 2004; 135:429-37.

11. Osorio R, Toledana M, Liebana J. Environmental microbial contamination: pilot study in a dental surgery. Int Dent J 1995; 45: 352-57.

12.Leggat PA, Kedjarune U. Bacterial aerosols in the dental clinic: a review. Int Dent J. 2001; 51:39-44.

13.McKinley IB Jr, Ludlow MO. Hazards of laser smoke during endodontic therapy. J Endod 1994; 20: 559-59.

14.Ayliffe GAJ, Bab JR, Taylor LJ. Infection and spread of microorganisms. Chapter 3. In: Hospital acquired infections: Priciples and Preventions. 3rd Edition 1999; Pg. No. 38-40.

15.Larato DC, Ruskin PF, Martin A. Effect of an ultrasonic scaler on bacterial counts in the air. J Periodontol 1967; 38:550-54.

16 Harrel SK, Rivera-Hidalgo F, Barnes JB. Reduction of aerosols produced by ultrasonic scalers. J Periodontol 1996; 67: 28-32.

17.Grenier D. Quantitaive analysis of bacterial aerosols in two different dental clinic environments. Appl Environ Microbiol 1995; 61: 3165-68.

18.Kedjarune U, Kukiattrakoon B, Yapong B, Chowanadisai S, Leggat P. Bacterial aerosols in the dental clinic: effect of time, position and type of treatment. Int Dent J. $2000 ; 50$ :103-7.

19.Stetzenbach LD. Introduction to Aerobiology, Chapter 72. In: Manual of environmental Microbiology, 2nd ed. Hurst CJ, Crawford RL, Knudsen G, McInerney M, Stetzenbach LD, Eds. 1995:77-86.

20.Prospero E, Savini S, Annino I. Microbial aerosol contamination of dental health care workers' faces and other surfaces in dental practice. Infect Control Hosp Epidemiol. 2003 ; 24: 139-41.

21.Sawyer LA, Murphy JJ, Kaplan JE, Pinsky PF, Chacon D, Walmsley $\mathrm{S}$ et al. 25- to $-30 \mathrm{~nm}$ virus particle associated with a hospital outbreak of acute gastroenteritits with evidence for airborne transmission. AM J Epidemol 1988; 127: 1261-71.

22.Burge H. Bioaerosols: prevalence and health effects in the indoor environment. J Allergy Clin Immunol 1990; 86: 687-01.

23 Harrel SK, Rivera-Hidalgo F, Barnes JB. Aerosol and splatter production by focused spray and standard ultrasonic inserts. J Periodontol 1999; 70: 473-77.

24.Wirthlin MR, Choi JH, Kye SB. Use of chlorine dioxide mouthrinse as the ultrasonic scaling lavage reduces the viable bacteria in the generated aerosols. J West Soc Periodontol Periodontal Abstr 2006; 54:35-44.

25.Bay NL, Overman PR, Krust-Bray K, Cobb C, Gross KB. Effectiveness of antimicrobial mouthrinses on aerosols produced by an air polisher. J Dent Hyg. 1993; 67:312-7.

26.Abichandani SJ, Nadiger R. Cross-contamination in dentistry: A comprehensive overview. Chron Young Sci 2013; 4: 51-8.

27.King TB, Muzzin KB, Berry CW, Ander LM. The effectiveness of an Aerosol reduction device for ultrasonic scalers. J Periodontol 1997; 68: 145-49.

28. Hallier C, Williams DW, Potts AJC, Lewis MAO. Summary of: A pilot study of bioaerosol using an air cleaning system during dental procedures. Br Dent Jour 2010; 8: 408-9.

29.Siegel JD, Rhinehart E, Jackson M, Chiarello L. Healthcare Infection Control Practices Advisory Committee, 2007 Guideline for Isolation Precautions: Preventing Transmission of Infectious Agents in Healthcare Settings.

How to cite this article:

Pulluri P, Karibasappa SN, Mehta DS, Aerosol and Splatter in Dentistry - An overview CODS J Dent 2015;7: $28-32$.

Source of support: Nil. Conflict of interest: None Declared. 